INDEXIA: Informatic and Computational Intelegent Journal Vol. 2, No. 1, Mei 2020, 38-41

P-ISSN: 2657-0424, E-ISSN: 2657-0432

\title{
MENINGKATKAN RELIABILITAS JARINGAN CLIENT SERVER DENGAN MENGGUNAKAN METODE VIRTUAL ROUTER REDUDANCY PROTOCOL (VRRP) BERBASIS CISCO DI PT.TRANS-PACIFIC PETROCHEMICAL INDOTAMA (TPPI) TUBAN
}

\author{
Heri Kusriyanto \\ PT Trans-Pacific Petrochemical Indotama (TPPI) \\ Email: hkusriyanto@gmail.com
}

\begin{abstract}
ABSTRAK
Dalam komunikasi jaringan Metro Ethernet (Metro-E) wide area network (WAN) perlu diperhatikan kemungkinan akan terjadinya gangguan pada router. Virtual Router Redudancy Protocol (VRRP) merupakan protocol redundancy standar Cisco yang menetapkan sebuah standby router dan active router yang disebut dengan istilah master router dan router lainnya menjadi backup router. Selain itu juga mempunyai virtual router. Virtual router didefinisikan melalui Virtual Router Identifier (VRID) dan IP address. Pemilihan master router juga dipengaruhi oleh nilai priority, semakin besar priority maka router tersebut akan menjadi master router. VRRP mempunyai 3 state, yaitu master, initialize, dan backup. Initialize adalah keadaan router pada saat menunggu adanya suatu even, state backup mempunyai tujuan untuk melakukan monitoring terhadap master router, jadi apabila master router down maka backup router akan mengambil alih tugas master router. State master mempunyai fungsi mengirimkan data ke router backup dengan dibuktikan packet loss $0 \%$ dengan delay waktu 1,0085 ms. Tiap router akan mengirimkan hello packet didalam VRRP disebut dengan advertisement interval. secara default advertisement interval adalah 1 detik. Hal ini di gunakan untuk mengecek apakah router mengalami down atau jalur terputus, sehingga untuk hal ini fungsi layanan jaringan client server sangat di butuhkan oleh perusahaan PT.Trans - Pacific Petrochemical Indotama (TPPI) dalam melakukan syncronisasi client server antar kantor pusat Jakarta dan site plant Tuban guna meningkatkan stabilitas jaringan yang terjaga
\end{abstract}

Kata kunci : Jaringan client server, VRRP, VRID, dan Downtime

\section{PENDAHULUAN}

PT. Trans-Pacific Petrochemical Indotama (TPPI) dalam mengelolah bisnis perusahaan yang berkantor pusat di Jakarta dan site plant yang berada di Tuban memiliki jaringan link jalur utama yang saling terintegrasi melalui jaringan Metro Ethernet (Metro-E) Wide Area Network (WAN). Router yang digunakan adalah CISCO sebagai media dalam komunikasi client-server, e-mail, file sharing, voip telephone dan akses aplikasi internal web perusahaan.

Pada infrastruktur jaringan link utama Peer to Peer (P2P) menggunakan Metro Ethernet (Metro-E) $10 \mathrm{Mbps}$ ICON Plus dan 10 Mbps ISAT sebagai link backup atau redundant untuk mengantisipasi jika link utama mengalami kegagalan disediakan Peer to Peer (P2P) Metro-E 10 Mbps ISAT. Selama periode tahun 2017 permasalahan seringnya terdapat kasus link utama 10 Mbps ICON Plus mengalami kegagalan yang sering diakibatkan oleh cuaca maupun perbaikan jalur link oleh provider penyedia layanan Metro-E. Selain itu kerusakan perangkat jaringan yang berakibat pada tidak bisa diaksesnya aplikasi internal web perusahaan yang digunakan plant serta komunikasi email tidak bisa terhubung ke plant site Tuban yang bersumber dari kantor pusat Jakarta. Langkah pertama yang dilakukan jika link utama mengalami kegagalan adalah dengan cara menjalankan sebuah script routing router secara manual pada sebuah program script jaringan router agar jalur link backup mengambil alih peran (failover) link utama yang mengalami kegagalan. Namun pada perpindahan dari link utama ke link backup, seringkali membutuhkan waktu perpindahan link pada router yang memakan waktu lama serta tidak termonitoring secara realtime pada saat jaringan down. Hal tersebut tentu saja mengurangi nilai availability dan reliability suatu jaringan Metro-E WAN yang mempunyai peranan penting di TPPI.

Melihat permasalahan tersebut, solusi yang diusulkan pada TPPI adalah membuat script konfigurasi routing jaringan pada router CISCO berjalan automatis ketika jalur Metro-E WAN utama down dan pindah ke jalur Metro-E backup sehingga komunikasi client server, $e$ mail, file sharing, Voip Telepehone dan akses aplikasi internal web perusahaan bisa berjalan normal. Tujuan utama menyediakan jaringan Metro-E WAN link backup adalah untuk meningkatkan reliabilitas pelayanan jaringan dengan meminimalisir waktu downtime. Untuk mengatasi masalah tersebut dapat dilakukan dengan cara diterapkannya protokol redundancy yaitu Virtual Router Redudancy Protocol (VRRP), dimana VRRP adalah sebuah protokol untuk menentukan proses redundancy router dalam suatu network dengan melakukan pemilihan master router dan backup router berdasarkan priority. Pada link utama dan backup melewati router yang berbeda tetapi dengan Virtual Router Identifier (VRID) yang sama. Fungsi tugas dari VRID ini untuk 
INDEXIA: Informatic and Computational Intelegent Journal

Heri Kusriyanto

Meningkatkan Reliabilitas Jaringan Client Server Dengan Menggunakan Metode Virtual Router Redudancy Protocol (Vrrp) Berbasis Cisco Di Pt.Trans-Pacific Petrochemical Indotama (Tppi) Tuban

memastikan bahwa kedua router masih di segmen yang sama.

\section{VRRP}

Virtual Router Redundancy Protocol (VRRP) (R. Hinden, April, 2004) adalah protocol yang dikembangkan oleh IEEE ini memiliki tujuan yang sama yaitu REDUNDANCY. Fungsi VRRP itu sendiri adalah menyediakan backup gateway, sehingga apabila primary gateway (master) failed traffic akan dilewatkan ke secondary gateway (backup) (Hinden. Robert, 2004).

VRRP dirancang untuk digunakan di multiaccess, multicast maupun broadcast dengan menggunakan ethernet LAN. VRRP tidak dimaksudkan sebagai pengganti dari protokol dinamis yang ada. VRRP mendukung Ethernet, Fastethernet, Bridge Group Virtual Interface (BVI), Gigabit Ethernet interfaces dan pada Multiprotocol Label Switching (MPLS), Virtual Private Networks (VPNs).

Mekanisme kerja dari protokol ini terimplemetasikan dalam sebuah Virtual router atau VRRP group. Virtual router merupakan sekumpulan router yang difungsikan untuk kebutuhan redundancy. Jumlah router yang dapat diaplikasikan bisa lebih dari satu untuk membentuk sebuah virtual router atau lebih. Pada VRRP akan ada sebuah router yang berperan sebagai master dan ada satu atau beberapa router yang berperan sebagai backup. High Availability sistem akan terjaga dengan aplikasi VRRP ini pada sebuah jaringan. Hal ini bisa terjadi karena ketika main-link mengalami down maka paket data masih tetap akan bisa dilewatkan melalui link lainnya.

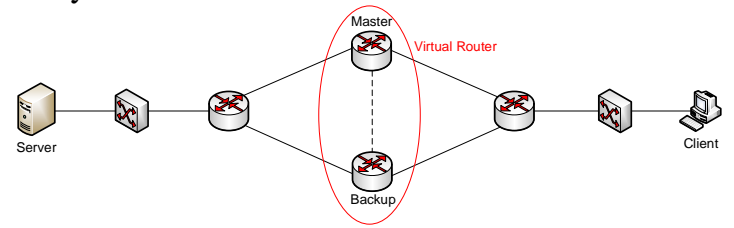

Gambar 1 Topologi VRRP.

\subsection{Mekanisme VRRP.}

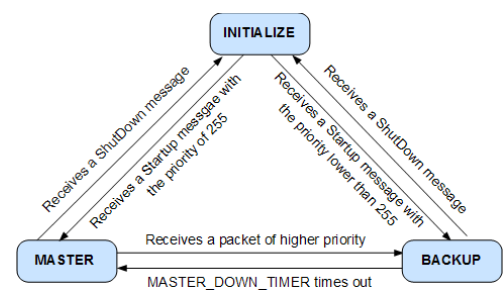

Gambar 2. Cara Kerja VRRP

Gambar 2: Initialize state mengirimkan Startup message ke 2 perangkat switch dengan prioritas 255 untuk Master state dan prioritas dibawah 255 untuk Backup state. Hal tersebut dilakukan karena untuk memberikan pemberitahuan bahwa perangkat tersebut merupakan Master atau Backup. Kemudian Master dan Backup mengirimkan pesan kepada Initialize state mengenai statusnya mati atau hidup.

\subsubsection{VRRP Simulasi}

Design Simulasi jaringan VRRP ini mengunakan GNS3 dengan 4 router dan 2 switch layer 2 serta VPCS sebagai client - server .

Router version IOS cisco GNS3 dapat di gunakan konfigurasi sama persis dengan aktualnya sehingga implementasi VRRP jaringan sangat mendukung sekali sebagai jaringan sesungguhnya. Adapun implementasi VRRP pada gambar 3 .

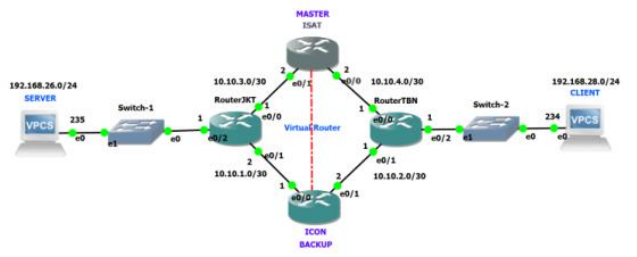

\section{Gambar 3. Jaringan VRRP}

Untuk konfigurasi jaringan VRRP masing - masing router sebagai berikut :

Router Jakarta

RouterJKT\#conf $t$

RouterJKT (config) \#int eth $0 / 1$

RouterJKT (config-if) \#vrrp 1 priority 200

RouterJKT (config-if) \#vrrp 1 ip 10.10.1.3

RouterJKT (config-if) \#vrrp 2 priority 100

RouterJKT (config-if) \#no vrrp 2 preempt

RouterJKT (config-if) \#vrrp 2 ip 10.10.1.4

RouterJKT (config) \#exit

RouterJKT\#conf $t$

RouterJKT (config) \#int eth $0 / 0$

RouterJKT (config-if) \#vrrp 1 priority 100

RouterJKT (config-if) \#vrrp 1 ip 10.10.1.3

RouterJKT (config-if) \#vrrp 2 priority 200

RouterJKT (config-if) \#no vrrp 2 preempt

RouterJKT (config-if) \#vrrp 2 ip 10.10.1.4

RouterJKT (config) \#exit

RouterJKT\#

Router Tuban 
INDEXIA: Informatic and Computational Intelegent Journal

Heri Kusriyanto

Meningkatkan Reliabilitas Jaringan Client Server Dengan Menggunakan Metode Virtual Router Redudancy

Protocol (Vrrp) Berbasis Cisco Di Pt.Trans-Pacific Petrochemical Indotama (Tppi) Tuban

RouterTBN (config) \#int eth

RouterTBN (config) \#int ethernet $0 / 0$

RouterTBN (config-if) \#vrrp 1 priority 100

RouterTBN (config-if) \#no vrrp 1 preempt

RouterTBN (config-if) \#vrrp 1 ip 10.10 .4 .4

RouterTBN (config-if) \#vrrp 2 priority 200

RouterTBN (config-if) \#vrrp 2 ip 10.10.4.5

RouterTBN (config-if) \#exit

RouterTBN (config) \#int eth

RouterTBN (config) \#int ethernet $0 / 1$

RouterTBN (config-if) \#vrrp 1 priority 200

RouterTBN (config-if) \#no vrrp 1 preempt

RouterTBN (config-if) \#vrrp 1 ip 10.10 .4 .4

RouterTBN (config-if) \#vrrp 2 priority 200

RouterTBN (config-if) \#vrrp 2 ip 10.10.4.5

RouterTBN (config-if) \#exit

Router Master

ISAT\#conf $t$

ISAT (config) \#int eth $0 / 0$

ISAT(config-if)\#ip add 10.10.4.2 255.255.255.0

ISAT (config-if) \#no shutdown

ISAT (config-if) \#exit

ISAT (config) \#int eth $0 / 1$

ISAT (config-if) \#ip add 10.10.3.2 255.255.255.0

ISAT (config-if) \#no shut

ISAT (config-if) \#exit

ISAT\#

Router Backup

ICON\#COnf $t$

ICON (config) \#int eth $0 / 0$

ICON(config-if) \#ip add 10.10.1.1 255.255.255.0

ICON (config-if) \#no shutdown

ICON (config-if) \#exit

ICON(config) \#int eth $0 / 1$

ICON (config-if) \#ip add 10.10.2.1 255.255.255.0

ICON (config-if) \#no shut

ICON (config-if) \#exit

ICON\#

\section{METODE PENELITIAN}

Konsep pengelolaan jaringan dengan memanfaatkan Routing VRRP (Virtual Router Redundancy Protocol) dengan failover serta meman

\section{HASIL DAN PEMBAHASAN}

Dilakukan implementasi dengan koneksi client ke server yang sudah selesai dan sukses dapat dibuktikan koneksinya dengan lakukan printah ping dan trace ke server tujuan maupun sebaliknya ke client.

CLIENT> ping 192.168.26.235 (IP Server Jakarta)

84 bytes from 192.168.26.235 icmp_seq=1 ttl=61 time $=61.779 \mathrm{~ms}$

84 bytes from 192.168 .26 .235 bytes from 192.168 .26 .235 icmp_seq $=3$ tt $=61$ time $=54.878 \mathrm{~ms}$

84 bytes from 192.168 .26 .235 i cmp seq $=4$ ttl $=61$ time $=58.604 \mathrm{~ms}$

84 bytes from 192.168.26.235 icmp_seq=5 ttl=61 time $=55.999 \mathrm{~ms}$

CLIENT> trace 192.168.26.235 ( IP Server Jakarta)

trace to $192.168 .26 .235,8$ hops max, press Ctrl+C to stop

$1 \quad 192.168 .28 .1 \quad 6.243 \mathrm{~ms} 1.996 \mathrm{~ms} 9.261 \mathrm{~ms}$

$\begin{array}{lllll}2 & 10.10 .4 .2 & 30.225 \mathrm{~ms} & 29.892 \mathrm{~ms} & 32.041 \mathrm{~ms} \\ 3 & 10.10 .3 .1 & 50.866 \mathrm{~ms} & 51.183 \mathrm{~ms} & 51.873 \mathrm{~ms}\end{array}$

SERVER> ping 192.168.28.234 ( IP Client Tuban)

84 bytes from 192.168.28.234 icmp_seq=1 ttl $=61$ time $=64.463 \mathrm{~ms}$

84 bytes from 192.168 .28 .234 icmp seq $=2$ ttl $=61$ time $=60.740 \mathrm{~ms}$

84 bytes from 192.168.28.234 icmp_seq $=3$ ttl $=61$ time $=54.595 \mathrm{~ms}$

84 bytes from 192.168.28.234 icmp_seq=4 ttl $=61$ time $=57.268 \mathrm{~ms}$

84 bytes from 192.168 .28 .234 icmp_seq=5 ttl=61 time $=63.844 \mathrm{~ms}$

SERVER> trace 192.168.28.234 (IP Client Tuban)

trace to $192.168 .28 .234,8$ hops max, press Ctrl+C to stop $\begin{array}{lllll}2 & 10.10 .1 .1 & 30.257 \mathrm{~ms} & 29.922 \mathrm{~ms} & 29.767 \mathrm{~ms} \\ 3 & 10.10 .2 .1 & 51.533 \mathrm{~ms} & 50.944 \mathrm{~ms} & 49.892 \mathrm{~ms}\end{array}$

Dan implementasi dengan jaringan VRRP ketika terjadi master down.

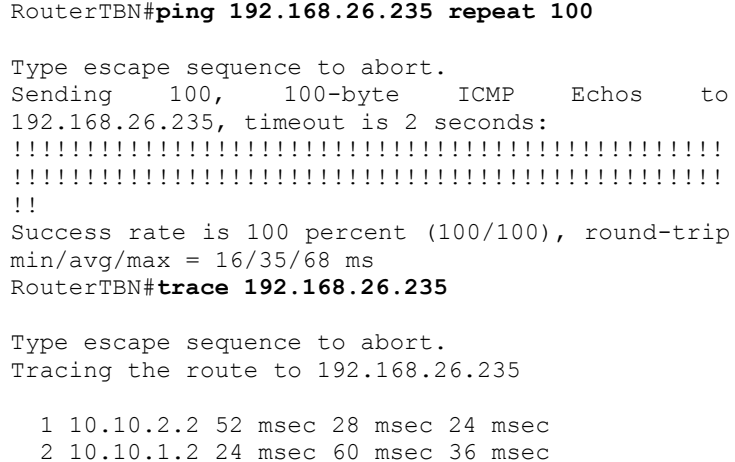

\section{KESIMPULAN DAN SARAN}

Berdasarkan hasil pengujian dan analisis yang telah dilakukan, maka dapat disimpulkan beberapa hal sebagai berikut :

1. Berdasarkan hasil pengujian menggunakan protokol redudancy VRRP (Virtual Router Redundancy Protocol) ketika link ataupun perangkat router master mengalami kegagalan, maka secara otomatis link dan router backup mengambil alih fungsi dari router utama.

2. Pada hasil pengujian menunjukan bahwa ketika jaringan redundancy menggunakan protokol VRRP lalu link ataupun router utama mengalami kegagalan, maka secara cepat link dan router backup mengambil alih fungsi dari router utama dengan di buktikan packet loss $0 \%$ dengan delay $1,0085 \mathrm{~ms}$ sehingga total kehilangan karena collision dan congestion pada jaringan sangat berpengaruh pada semua beban applikasi yang sedang berjalan.

3. Pada hasil pengujian pada saat perpindahan dari router utama ke backup router memiliki waktu downtime yang singkat, rata-rata ketika terjadi satu kegagalan memerlukan waktu dibawah satu menit untuk dapat berfungsi kembali secara normal.

\section{SARAN}

Dari hasil peneliatian dan implementasi ini masih banyak kekurangan dan memungkinkan untuk dikembangkan lebih lanjut, diantaranya :

A. Di harapkan performence kwalitas jaringan VRRP terutama delay pada Qos yang terjadi pada saat terjadinya down jaringan client server berpindah secara normal lebih kurang 1 menit

B. Packet loss jaringan diharapkan nol agar performa lebih bagus. 
INDEXIA: Informatic and Computational Intelegent Journal

Heri Kusriyanto

Meningkatkan Reliabilitas Jaringan Client Server Dengan Menggunakan Metode Virtual Router Redudancy

Protocol (Vrrp) Berbasis Cisco Di Pt.Trans-Pacific Petrochemical Indotama (Tppi) Tuban

\section{DAFTAR PUSTAKA}

Constantine, B. (Mei, 2011). Framework for TCP Throughput Testing. IETF, RFC 6349, ISSN: 2070-1721, 20.

Firmansyah. (2018, January). Analisis Perbandingan Kinerja Jaringan CISCO Virtual Router Redundancy Protocol (VRRP) Dan CISCO Hot Standby Router Protocol (HSRP). Konferensi Nasional Sistem Informasi, STMIK Nusa Mandiri Jakarta.

G. Almes, S. K. (September, 1999). A One-way Delay Metric for IPPM. Advanced Network \& Services, RFC 2679, 9.

Oetomo, B. S. (2004). Konsep dan Perancangan Jaringan Komputer. Yogyakarta: Penerbit ANDI.

R. Hinden, E. (April, 2004). Virtual Router Redundancy Protocol (VRRP). RFC 3768, 3.

Rajamohan, D. P. (November, 2014). An Overview ofVirtual Router Redundancy Protocol Techniques and Implementation for Enterprise Networks. IJISET - International Journal of Innovative Science, Engineering \& Technology, Vol. I issue 9.

Ramadhita. (2011). Implementasi dan Analisis Performansi VRRP (Virtual Router Redundancy Protocol ) Pada Jaringan Inter VLAN (Inter Virtual LAN). Skripsi, Fakultas Elektro dan Komunikasi IT Telkom Bandung.

Sukmaaji, A. R. (2008). Jaringan Komputer. Konsep Dasar Pengembangan Jaringan Dan Keamanan Jaringan, Yogyakarta.

Yani, A. (2007). Panduan Membangun Jaringan Komputer. Jakarta: Penerbit Kawan Pustaka. 